\title{
GESTÃO ESCOLAR EM INSTITUIÇÕES DE ENSINO MÉDIO: ENTRE A GESTÃO DEMOCRÁTICA E A GERENCIAL
}

\author{
Antônio Cabral Neto* \\ Alda Maria Duarte Araújo CASTRo**
}

\begin{abstract}
RESUMO: A gestão democrática das escolas públicas encontra-se na agenda da política educacional do governo brasileiro, notadamente a partir das últimas décadas do século xx, e se amplia nos anos iniciais do século xxı. Essa mesma concepção tem se apresentado como uma demanda dos setores organizados dos educadores que, historicamente, pressionaram o poder público para criar mecanismos de gestão democrática para a administração das unidades escolares. Este artigo se debruça sobre essa temática, com base em resultados de uma pesquisa efetuada em escolas públicas estaduais, do ensino médio, do estado do Rio Grande do Norte, procurando destacar como a gestão escolar se organiza, considerando duas dimensões desse processo: o projeto político-pedagógico e os conselhos escolares. Os resultados do estudo evidenciam a implementação de mecanismos de gestão democrática nas escolas, mas também a presença de mecanismos gerenciais para conduzir as ações da escola.
\end{abstract}

Palavras-chave: Ensino médio. Participação. Gestão democrática. Gestão gerencial.

\section{EDUCATION MANAGEMENT IN HIGH SCHOOL INSTITUTIONS: BETWEEN DEMOCRATIC MANAGEMENT AND NEW PUBLIC MANAGEMENT}

\begin{abstract}
The democratic management of public schools, which has been present on the educational policy agenda of the Brazilian government, especially from the last decades of the $20^{\text {th }}$ century onwards, has widened in the early years of this century. It emerged as a demand of the organized sectors of educators who historically lobbied the government to create mechanisms of democratic governance to manage school units. Based on the results of a survey of state public high schools in the state of Rio Grande do Norte, this paper focuses on this theme to highlight how school management is organized. It takes two dimensions of this process into account: the political-pedagogical project and the school boards. Its results show the mechanisms for democratic management have been implemented in schools, but also that management mechanisms to conduct the school's actions are still present.
\end{abstract}

Key words: High school. Participation. Democratic management. Management.

\footnotetext{
* Doutor em Educação e professor do Programa de Pós-Graduação em Educação da Universidade Federal do Rio Grande do Norte (UFRN). E-mail: cabraln@ufrnet.br

** Pós-doutora em Educação e professora do Programa de Pós-Graduação em Educação da Universidade Federal do Rio Grande do Norte (UFRN).E-mail: alda@ufrnet.br
} 


\section{GESTION SCOLAIRE DES LyCÉES: ENTRE GESTION DEMOCRATIQUE}

\section{ET NOUVELLE GESTION PUBLIQUE}

RÉSUMÉ: La gestion démocratique des écoles publiques, qui est inscrite sur l'agenda des politiques éducatives du gouvernement brésilien, surtout depuis les dernières décennies $d u x^{e}$ siècle, s'est élargie dans les premières années de ce siècle. Elle a surgi comme une demande des secteurs organisés d'éducateurs qui, historiquement, ont exercé une pression sur le gouvernement pour qu'il crée des mécanismes de gouvernance démocratique pour les écoles. A partir des résultats d'une recherche menée dans les lycées publics de l'état du Rio Grande do Norte, cet article se centre sur ce thème pour comprendre comment la direction de l'école est organisée, en considérant deux dimensions de ce processus: le projet politico-pédagogique et les conseils scolaires. Les résultats démontrent la mise en œuvre de mécanismes de gestion démocratique dans les écoles, mais aussi la présence de mécanismes de gestion pour mener des actions de l'école.

Mots-clés: Lycée. Participation. Gestion démocratique. Nouvelle gestion publique.

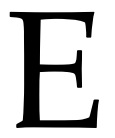

ste artigo desenvolve uma reflexão sobre a gestão escolar em instituições públicas estaduais, do ensino médio, do estado do Rio Grande do Norte. A análise dessa temática parte do pressuposto de que a explicação para o formato que assume a gestão escolar, em contextos particulares, embora guarde as suas especificidades, traz elementos constitutivos do cenário sociopolítico e econômico no qual ela se desenvolve. Com esse entendimento, o artigo está organizado em três partes que se articulam e dão sentido à reflexão proposta: uma discussão sobre os elementos contextuais que caracterizam o momento de emergência de novos modelos de gestão para o setor público; uma reflexão sobre a gestão escolar, pondo em evidência duas possibilidades: a gestão gerencial e a gestão democrática; a gestão escolar no ensino médio e as particularidades em escolas públicas estaduais do Rio Grande do Norte.

\section{O cenário das reformas}

A reforma educacional implementada no Brasil, nas últimas décadas, ocorreu no âmbito da redefinição do papel do Estado, tomando, como referência, os pressupostos neoliberais, a globalização da economia e a reestruturação produtiva. Essa conjuntura criou condições para o surgimento de paradigmas econômicos mais flexíveis que vêm substituindo o modelo taylorista/fordista, em uma tentativa de responder às novas configurações assumidas pelas economias internacionais. As inúmeras transformações que estão ocorrendo na esfera da produção, do mercado e do Estado fazem parte de um mesmo movimento histórico em que o capitalismo busca estratégias para a sua recomposição (Harvey, 1992; Anderson, 1995).

Essas mudanças ocorrem pela crescente incorporação de ciência e de tecnologia ao processo de trabalho, mediante a substituição de tecnologias rígidas por 
outras de base eletroeletrônica, imprimindo inovações nas áreas de materiais e equipamentos. Para Kuenzer (1992, p. 457), essa dinâmica vem causando "profundos impactos sobre os processos pedagógicos, passando-se a exigir do homem novos conhecimentos e novas atitudes no exercício de suas múltiplas funções, enquanto ser social, político e produtivo".

Um novo perfil de qualificação é definido para o trabalhador, exigindo escolaridade básica, capacidade de adaptação a novas situações, compreensão de tarefas complexas, atenção e responsabilidade, atitude de abertura para novas aprendizagens, criatividade e capacidade de comunicação grupal (Machado, 1994).

Essas transformações que ocorrem no mundo do trabalho vão se manifestar nas formas de organização e de administração das empresas e nas relações de trabalho, provocando, também, mudanças nos padrões de intervenção estatal que resultaram na emergência de novos mecanismos e de novas formas de gestão, redirecionando as políticas públicas e, particularmente, as educacionais.

A reforma educacional em curso no Brasil insere-se na lógica desse processo de adaptação da força de trabalho às novas exigências do capital, ao mesmo tempo em que se articula com a necessidade de redefinição do papel do Estado, o qual deixa de ser o responsável direto pelo desenvolvimento econômico e social (por meio da redução de seu papel intervencionista), para se fortalecer na função de promotor e regulador desse desenvolvimento.

A reforma educacional, em consonância com tais orientações, tem priorizado os seguintes eixos: a) focalização de programas - procura-se substituir o acesso universal aos direitos sociais e bens públicos por acesso seletivo; b) descentralização - possibilita a utilização de estratégias para propiciar a democratização do Estado e a busca de maior justiça social; c) privatização - entendida, no seu sentido mais amplo, como a transferência das responsabilidades públicas para organizações ou entidades privada; d) desregulamentação - que tem por objetivo criar um novo quadro legal com vistas a diminuir a interferência dos poderes públicos sobre os empreendimentos educacionais privados. Esse princípio realiza-se pelo ajuste da legislação e dos métodos de gestão das instituições educacionais às novas diretrizes propostas para a política educacional e vem influenciando diretamente a organização e a gestão do sistema educacional, interferindo na formulação e na condução das políticas para o campo, determinando novos papéis e funções para os profissionais da educação, em todos os níveis de atuação.

\section{O gerencialismo e sua influência no campo da gestão escolar}

No conjunto das mudanças que se processaram no cenário social, nas últimas décadas, emerge a necessidade de alterações significativas na gestão pública 
em todos os níveis. Essas mudanças se materializam na concepção de um novo modelo de gestão que se propunha a superar o modelo burocrático de orientação weberiana, considerando que ele enfrentava problemas e não respondia mais às necessidades circunscritas àquele momento.

Segundo Paramio (2004), as estratégias básicas das reformas estruturais consistiam não só em diminuir a intervenção do Estado na economia, mas também reduzir as suas próprias dimensões. Isso supunha a privatização de empresas e serviços públicos que pudessem ser transferidos à iniciativa privada. A adoção dessas medidas traria maiores investimentos para os países e poderia desencadear uma dinâmica de crescimento, que não somente incrementaria os recursos fiscais do Estado, mas também eliminaria a situação de vulnerabilidade dos países em relação ao atendimento dos serviços sociais para a população.

Na segunda metade dos anos de 1990, conforme o referido autor, foi ficando evidente que as promessas das reformas estruturais não se cumpriram em sua plenitude, denotando, portanto, a necessidade de criação de um novo programa prescritivo para atender aos requerimentos dessa nova fase da crise. Isso se materializou pelo que se convencionou chamar de reformas de segunda geração, centradas no pressuposto de que era necessário reformar o contexto institucional. Assim, surgiram medidas para a melhoria da qualidade da administração, do sistema judicial e político. Essas reformas tinham como objetivos reformular a legislação, a administração pública e a estrutura do governo central para imprimir maior governabilidade ao Estado.

Dessa forma, a administração pública começa a se reestruturar levando em consideração, também, o processo e os resultados das políticas públicas, tomando como matriz os eixos da eficiência, da eficácia e da produtividade. O modelo gerencial para o serviço público foi importado da iniciativa privada, e a Grã-Bretanha pode ser considerada o laboratório das técnicas gerenciais aplicadas ao setor público. Outros países, como a Austrália e Nova Zelândia, também implementaram reformas no setor público. No entanto, apesar das características comuns às experiências de reforma, não há um sentido unívoco, ou um único paradigma organizacional que guie todas as nações no que concerne à implementação das orientações de um novo modelo de gestão.

O ponto de apoio da reforma gerencial é a busca da eficiência, pela redução e controle dos gastos públicos, pela demanda de melhor qualidade dos serviços públicos, pela descentralização administrativa, concedendo maior autonomia às agências e departamentos. Há preocupação, portanto, com o produto em detrimento dos processos.

Esse modelo vem sendo reestruturado e na atual fase de sua reorganização - denominada de Public Orientation Service - representa um imbricamento das ideias gerenciais concebidas no âmbito do setor privado com as ideias já formuladas para 
o setor público nas fases anteriores do gerencialismo (modelo gerencial puro e consumerism), revalorizando os gestores públicos pela incorporação da noção de gestão de qualidade que pode ser buscada no setor privado.

Esse modelo está em consonância com os princípios da nova gestão pública, cujo fulcro é a melhoria do desempenho governamental e tem como objetivo a reconstrução do Estado em novas bases, tornando necessário definir as suas funções e as suas formas de atuação, além de incrementar a governança estatal (governance), mediante a profissionalização da burocracia pública, o fortalecimento de seus instrumentos gerenciais e a melhoria do seu desempenho na elaboração de políticas públicas (Abrucio, 2003).

Bresser Pereira (1998) argumenta que, apesar da reforma da administração pública procurar a sua inspiração na administração privada, dela se diferencia, por não visar ao lucro, mas ao interesse público. Ainda segundo o autor, a reforma gerencial objetiva: aumentar a eficiência e a efetividade dos órgãos e agências do Estado, melhorar a qualidade das decisões estratégicas do governo e sua burocracia e assegurar o caráter democrático da administração pública. Esse mesmo entendimento pode ser encontrado no Documento do Centro Latino-Americano para o Desenvolvimento (CLAD, 2006), que assegura, mesmo inspirado na iniciativa privada, que o modelo gerencial deve, impreterivelmente, se adequar ao contexto político democrático no qual está inserido. Isso porque a especificidade da organização governamental é atuar conforme o interesse público enquanto as empresas buscam o lucro.

A nova gestão pública atuaria mais como um depósito de orientações, métodos e técnicas do que como um conjunto sistemático e ordenado de propostas que devem ser utilizadas de acordo com problemas específicos, com os objetivos a alcançar e, ainda, conforme as forças de apoio e resistência à mudança. Isso explicaria a diversidade de reformas que têm sido empreendidas em nível dos Estados-nações. Uma das suas características é se apresentar como politicamente neutra. Sua hegemonia e sua ampla difusão devem-se à sua capacidade de dar resposta aos dilemas do mundo atual e, especificamente, aos gerados pelos altos custos e pelos baixos resultados das burocracias (Gete, 2001; Barzelay, 1998).

As propostas da nova gestão pública são amplas e variadas, bem como a sua utilização. Nela, se podem encontrar desde instrumentos ou tecnologias que, por sua própria natureza, têm um êxito bastante circunstancial e mudam com extraordinária rapidez, como proposta da melhor maneira de tratar as relações entre as organizações públicas e os cidadãos para a provisão de serviços.

Segundo Gete (2001), as principais recomendações constantes do planejamento da nova gestão pública - que, em seu conjunto, têm a pretensão de constituir alternativas aos modelos tradicionais de gestão - são: 
a) redução do tamanho do setor público no que concerne ao seu tamanho e ao seu âmbito de atuação, aos seus recursos e ao seu grau de influência. As políticas implementadas na década de 1970 responderam, claramente, a esse imperativo e se consubstanciaram no processo de privatização;

b) redução das hierarquias, que consiste na descentralização das funções e na eliminação da abundância dos escalões hierárquicos;

c) rupturas com o monolitismo e a especialização, fundada na ideia de pôr fim às grandes organizações administrativas, criando, em seu lugar, organizações menores e mais adaptadas ao seu entorno. Aqui, o que está em evidência é a ideia de "agência" caracterizada pela sua não vinculação hierárquica. O sistema de "agência" implica a criação de unidades gestoras independentes das estruturas centrais;

d) clientelização, que traz uma nova visão do usuário do serviço público. Nessa nova visão, é importante compreender que o cliente não é alguém sobre quem se exerce uma autoridade; ao contrário, deve ser alguém a quem se serve. A mudança do conceito de usuário ao de cliente significa converter o serviço público em serviço ao público, em que cada cidadão pode transmitir sua própria visão da prestação do serviço que recebe, de sua utilidade e de suas preferências;

e) descentralização das organizações.

Esse modelo de gerenciamento, como assinala Santos (1999), é contrário a uma refundação democrática da administração pública. A lógica do gerencialismo, na compreensão do autor, está em consonância com o modelo de Estado-empresário, que tem como meta precípua promover as condições adequadas para propiciar a concorrência entre os serviços públicos. Esse padrão estatal transforma o cidadão em consumidor e descentraliza o poder, segundo os mecanismos de mercado.

\section{Descentralização como uma das estratégias da gestão gerencial}

Particularmente no que concerne à descentralização - aspecto relevante na administração gerencial -, argumenta-se que ela propicia as condições favoráveis para tornar mais eficazes as políticas públicas; aproxima o centro de decisões dos serviços públicos dos consumidores, assegurando-lhes o direito de escolher os equipamentos sociais que oferecem melhor qualidade; permite que os cidadãos participem das decisões que afetam suas vidas.

O fulcro desse processo está centrado em uma dinâmica, na qual se materializa uma desconcentração de responsabilidades em direção à ponta do sistema 
e não do poder de decisão dos níveis hierarquicamente inferiores da organização administrativa. Com essas características, a participação se metamorfoseia em uma técnica de gestão propiciadora de coesão e consenso, despolitizando, assim, o processo de participação dos sujeitos sociais na formulação, implementação e avaliação da política.

O desafio de promover a eficiência pública não pode se reduzir a um problema estritamente gerencial. Como assinala Quirós (2006), a transformação do Estado como processo integral que procure níveis crescentes de eficiência só faz sentido se as ações desenvolvidas conduzirem a um maior bem-estar social, refletido em melhoria na qualidade de vida da população.

Reforça-se o argumento de que a descentralização nem sempre funciona como elemento estimulador da democratização da ação estatal. Muitas vezes, ela se apresenta, apenas, como uma forma mais eficiente de controle dos gastos públicos. O processo de descentralização atualmente em desenvolvimento no sistema educacional não foi, necessariamente, resultado das conquistas democráticas por parte dos movimentos sociais, embora reconheçamos a sua importância nessa dinâmica, nos últimos anos, na sociedade brasileira.

Nessa compreensão, a descentralização foi motivada, entre outros fatores, pelo enfraquecimento do poder central e de suas entidades administrativas, que não conseguiram acomodar interesses provenientes de novas demandas da população. A descentralização apresenta-se, nesse momento, como uma solução para administrar as insatisfações diversas em relação ao Estado autoritário, ao déficit nos serviços públicos e às dificuldades financeiras e insuficiências administrativas (Offe, 1984).

Essa visão de descentralização é incorporada pelo Estado brasileiro e tem servido de referência para nortear as reformas propostas pelo governo. Ela facilita a redução da ação estatal e a entrada, no setor educacional, de práticas de gestão próprias do setor privado. Procura-se, com isso, aproximar o sistema do consumidor, oportunizando respostas mais ágeis do sistema às suas expectativas, e diminuir a estrutura hierárquica dentro do sistema, possibilitando decisões mais próximas ao local de execução das políticas (Offe, 1984). Procura-se, ademais, construir o entendimento de que os cidadãos resolvem, na esfera local, todos os problemas do setor público e que devem ser responsabilizados pelo sucesso ou o fracasso da política.

O modelo gerencial vem sendo adotado como orientação na gestão pública em todos os níveis, incluindo as unidades escolares. Argumenta-se que a gestão nestas unidades, baseada em um modelo de administração caracterizado pela hierarquização, verticalização dos sistemas, burocratização dos processos e realizada, predominantemente, mediante o controle, não atende mais aos novos requerimentos do contexto social, delineado a partir das últimas décadas do século xx. A defesa 
assumida, nesse momento, direciona-se no sentido de se desenhar modelos de gestão escolar flexíveis, em acordo, portanto, com o movimento de reforma em gestação para o setor público no seu conjunto.

A defesa da descentralização pauta-se no entendimento de que é, preferencialmente, no âmbito local que é possível promover a gestão da escola e do processo educacional para a produção de melhores resultados. No entanto, torna-se necessário reconhecer que a descentralização, na área da educação, tem sido utilizada não apenas como estratégia de democratização, mas, sobretudo, como mecanismo para propiciar a melhoria na gestão de processos e recursos e, também, como condição para aliviar as instâncias centrais do sistema educacional, que se tornam sobrecarregadas com o crescimento das demandas (Barroso, 1998).

Nesse movimento, como diz Barroso (op. cit., p. 11), “o Estado devolve (para as escolas) as táticas, mas conserva as estratégias, ao mesmo tempo em que substitui um controle direto, centrado no respeito das normas e dos regulamentos, por um controle remoto, baseado nos resultados". O que vem se praticando nos sistemas educacionais, conforme Lück (2000, p. 18), caracteriza-se muito mais como

(...) a desconcentração, do que propriamente a descentralização, isto é, realiza-se a delegação regulamentada da autoridade, tutelada ainda pelo poder central, mediante o estabelecimento de diretrizes e normas centrais, controle na prestação de contas e a subordinação administrativa das unidades escolares aos poderes centrais, em vez de delegação de poderes de autogestão e autodeterminação na gestão dos processos necessários para a realização das políticas educacionais.

A descentralização, da forma como vem se consubstanciando no sistema educacional, tem se configurado como estratégia que pouco tem contribuído para o fortalecimento da gestão democrática (Cabral Neto \& Almeida, 2000), visto que não tem propiciado espaços significativos para que se construam níveis crescentes de participação política no âmbito das unidades escolares.

A reforma gerencial implementada tanto no nível do sistema educacional, quanto nos outros setores sociais, dirigida para a desestatização do setor público, para a descentralização e para a flexibilização, não contribui para a democracia. Esse tipo de reforma, como assinala Lustosa da Costa (2010, p. 236), é incapaz de alterar "as relações entre Estado e sociedade, valorizando o interesse do cidadão como titular de direito e consumidor de bens públicos, incorporando a sua participação, superando a neutralidade burocrática e mudando o sentido de responsabilidade pública".

A gestão educacional, em atendimento a esses novos requerimentos, passou a ser organizada de modo a otimizar os recursos e garantir a produtividade da escola, utilizando, para isso, um discurso de participação e autonomia. Exigem-se dos 
gestores habilidades e criatividade para encontrar novas soluções, sobretudo, para aumentar a eficiência, utilizando, entre outros mecanismos, os modelos de avaliação do desempenho.

No campo educacional, são perceptíveis as mudanças que ocorreram na gestão educacional, a partir do novo modelo gerencial adotado para os serviços públicos. A própria legislação educacional se encarregou de normatizar as ações da gestão educacional, para possibilitar uma gestão mais descentralizada, mais ágil e mais participativa. Embora a Constituição Federal de 1988 e a Lei de Diretrizes e Bases da Educação Nacional (Lei n. 9.394/96) se refiram à gestão democrática, os programas e projetos desenvolvidos pelos últimos governos se alinham, de fato, a uma perspectiva de gestão gerencialista. Entre eles podem-se citar o Plano de Desenvolvimento da Educação (PDE), o Plano Estratégico das Secretais (PES) e o Plano de Desenvolvimento da Escola (PDE-Escola). Este último é claramente indicado, pela equipe gestora das escolas participantes da pesquisa, como sendo o principal programa que hoje orienta as ações das escolas.

A reestruturação do Estado e as modificações assumidas pela nova gestão pública impactaram diretamente em toda a organização dos serviços públicos, trazendo mudanças também para a gestão educacional. Esse fato provocou mudanças na cultura organizacional da escola e na função do gestor escolar, que é chamado não só a gerenciar os serviços escolares, mas também a captar recursos, estabelecer parcerias e se responsabilizar pelo sucesso e pelo fracasso da escola.

Observa-se, na atual situação brasileira, a existência de um processo contraditório em que, ao mesmo tempo, se descentralizam algumas ações (quase sempre relacionadas à execução) e se recentralizam outras de caráter mais estratégico, relacionadas ao processo de tomada de decisão, evidenciando, desse modo, uma dinâmica em que o fulcro do processo não é o favorecimento do princípio da gestão democrática, mas, sobretudo, a busca de uma nova racionalidade centrada no gerenciamento dos recursos, objetivando o aumento da produtividade do sistema em moldes empresariais.

\section{Gestão democrática: um projeto em construção}

Nas últimas décadas, o tema da gestão democrática tem assumido relevância na agenda política e acadêmica. A sua defesa centra-se no princípio de que a melhoria dos sistemas escolares em todos os níveis requer, necessariamente, uma ampliação dos espaços de participação da sociedade na definição e implementação das políticas. A realização desse princípio exige mudanças substanciais nas organizações escolares e nas pessoas que nelas trabalham, considerando que o que tem prevalecido, historicamente, em nossas escolas, no geral, são práticas de gestão com 
características centralizadoras, fruto de uma cultura de autoritarismo, conformada na realidade brasileira. Essa é uma situação que vem sendo reconstruída, no país, na medida em que passos iniciais têm sido dados para a edificação de novas práticas que buscam superar as relações eivadas pelo autoritarismo, trilhando caminhos que podem representar um processo em construção da gestão democrática. O que se coloca no horizonte é a necessidade de se consolidar práticas democráticas com características duradouras, o que não será possível sem o desenvolvimento da consciência da importância da democracia em todos os níveis de atuação social.

Nessa lógica de argumentação, é pertinente assinalar a defesa de Cury (2005, p. 19), para quem a "gestão democrática é um princípio de Estado nas políticas educacionais que espelha o próprio Estado Democrático de Direito e nela se espelha, postulando a presença dos cidadãos no processo e no produto de políticas de governo". O autor lembra, ainda, que os cidadãos querem mais do que ser executores de políticas, querem ser ouvidos e ter presença em arenas políticas de elaboração e nos momentos de tomada de decisão.

Nesses termos, a gestão democrática tem como eixo fundante a busca pela efetivação da educação como direito social, assim como a universalização do acesso com permanência e qualidade socialmente referenciada. É uma prática políticopedagógica que procura estabelecer mecanismos institucionais capazes de promover a participação qualificada dos agentes educacionais e demais setores interessados na ação educativa, o que requer um engajamento coletivo na formulação das diretrizes escolares, no planejamento das ações, assim como na sua execução e avaliação.

A gestão democrática pode ser caracterizada como um espaço de descentralização do poder, de participação e de autonomia das instituições. Portanto, ela possibilita a construção da cidadania e deve ser considerada fundamental na formação do cidadão. Para Luck (2006), a gestão democrática possibilita a melhoria da qualidade da educação e, nesse sentido, a qualidade deve ser negociada, participativa, autorreflexiva, contextual/plural, processual e transformadora. Isso requer um debate permanente entre os indivíduos e os grupos que demonstram interesse em relação ao sistema educativo, que têm responsabilidades para com ele e são capazes de definir, de modo consensual, objetivos e prioridades.

A gestão democrática dos sistemas de ensino e das escolas públicas com essas características se coloca, hoje, como uma necessidade inadiável para promover a melhoria da qualidade do ensino e propiciar o efetivo exercício da cidadania. Segundo Bordignon (2005, p. 12), é nesse aspecto que

(...) se situa um dos desafios dos educadores: a democracia, assim como a cidadania, se fundamenta na autonomia. Uma educação emancipadora é condição essencial para a 
gestão democrática. Escolas e cidadãos privados da autonomia não terão condições de exercer uma gestão democrática, de educar para a cidadania.

Por ser representativa do interesse e do compromisso da escola e do seu entorno, a gestão democrática pode contribuir, significativamente, para o sucesso da escola. A mudança da noção de responsabilização - princípio caro ao gerencialismo - para uma visão de participação e envolvimento local nas decisões da escola desponta como fundamental para se buscar a qualidade da educação. Nesse sentido, Ferreira (2004, p. 305) afirma:

A gestão democrática da educação é hoje um valor já consagrado no Brasil e no mundo, embora ainda não totalmente compreendido e incorporado à prática social global e à pratica educacional brasileira e mundial. É indubitável sua importância como um recurso de participação humana e de formação para a cidadania. É indubitável sua necessidade para a construção de uma sociedade mais justa e igualitária. É indubitável sua importância como fonte de humanização.

Na realidade das escolas brasileiras, a gestão democrática é garantida na legislação, considerando que os princípios desta gestão estão estabelecidos na Constituição Federal de 1988 (art. 206, vi), que passou a considerar os direitos sociais como direitos universais de cidadania, o que requer o funcionamento da democracia participativa, e na Lei de Diretrizes e Bases da Educação Nacional (Lei n. 9394/96). Embora esse mecanismo esteja previsto na legislação, o seu processo de implementação é gradual e bastante moroso, visto que, no âmbito das escolas, conforme vem sendo evidenciado nos estudos desenvolvidos na área, registra-se uma tensão permanente entre a gestão gerencial e a gestão democrática, criando empecilho para avanços mais significativos nas práticas desta última no cotidiano escolar. Ao lado dessa constatação, outros fatores contribuem para a não efetivação da gestão democrática, entre os quais as precárias condições de trabalho na escola e a cultura centralizadora que dificulta a distribuição de poder entre os diferentes segmentos da escola.

É importante reafirmar o princípio da gestão democrática não apenas como possibilidade do desenvolvimento escolar, mas, sobretudo, como estratégia importante na construção da qualidade do ensino público. A gestão democrática deve ter como um dos seus pilares básicos a busca pela construção crescente de níveis de qualidade, situando a educação como direito inalienável de todo ser humano.

\section{O projeto político-pedagógico e os conselhos escolares como estra- tégias da gestão democrática}

A Lei de Diretrizes e Bases da Educação Nacional (Lei n. 9.394/96) estabelece que a gestão democrática seja orientada pelos seguintes pressupostos: a participação 
dos profissionais da educação na elaboração do projeto pedagógico da escola e a participação das comunidades escolar e local em conselhos escolares ou equivalentes.

A gestão democrática pressupõe o efetivo envolvimento e participação de todos os sujeitos na tomada de decisão do processo administrativo e no planejamento pedagógico escolar. Logo, considera-se de fundamental importância o projeto político-pedagógico (PPP) como instrumento de articulação entre os meios e os fins, fazendo o ordenamento de todas as atividades pedagógico-curriculares e a organização da escola, tendo em vista os objetivos educacionais.

O ppp apresenta-se como um dos mecanismos capaz de contribuir para o desenvolvimento da gestão democrática das instituições escolares. Isso pressupõe que a sua elaboração, implementação e avaliação se consubstanciem mediante uma ação participativa de todos os envolvidos direta e indiretamente com o processo educativo na unidade escolar, o que implica a construção de uma nova maneira de compreender a escola e o ato educativo (Veiga, 1995; Vasconcelos, 2003).

Ao buscar uma nova forma de organização da escola, o ppr deve pautar-se em princípios de solidariedade, de reciprocidade, de participação coletiva. Essa dinâmica exige uma gestão compartilhada, que busca superar a adoção de mecanismos de centralização e de controle hierárquico tradicional. Por meio de uma gestão participativa, haveria uma maior demanda de envolvimento e compromisso de todos os interessados no processo decisório da escola. Pais, alunos, professores e funcionários devem participar, auxiliando na tomada de decisões desde a fase do planejamento até a implementação e avaliação das ações escolares.

Outra estratégia que contribui, junto ao PPP, para o aperfeiçoamento da gestão democrática é a organização e implantação dos conselhos escolares. Estes podem se constituir em um mecanismo, por excelência, de participação da sociedade nas decisões e rumos da escola. Eles devem ser formados por todos os segmentos da comunidade escolar, incluindo pais, alunos, professores e demais funcionários e, para ter maior significado no contexto da gestão democrática, devem desempenhar funções deliberativas, consultivas e fiscalizadoras relativas às questões administrativas, financeiras e pedagógicas.

Como instância de participação coletiva, o conselho escolar é considerado um espaço institucional capaz de contribuir para superar a administração centralizada, até então, vigente na escola e, ao mesmo tempo, contribuir para edificar uma gestão democrática que envolva todos os que - direta ou indiretamente - atuam no processo educacional. Essa forma de conceber a gestão possibilita a aproximação não só entre os segmentos internos da escola, mas também entre a instituição educacional e a comunidade escolar. No entender de Werle (2003, p. 46), "os conselhos escolares, 
como um espaço de gestão democrática do ensino público, apresentam-se, também, como ambiente de promoção e liberdade, de pluralismo, de qualidade, de igualdade, de gratuidade e de valorização do professor".

Os conselhos escolares representam ainda um espaço de autonomia e participação, comprometido com a defesa do ensino público gratuito e de valorização dos professores. Ele possibilita a prática da discussão, a construção coletiva do conhecimento, o compartilhamento do poder decisório, propiciando aos seus membros uma formação mais consciente e mais crítica.

As potencialidades das ações desenvolvidas pelo conselho escolar estão exatamente na possibilidade de participação dos diferentes segmentos que compõem a unidade escolar. No entanto, a sua efetivação depende da mobilização de cada segmento. A implantação dos conselhos tem se mostrado insuficiente para provocar mudanças significativas no espaço escolar, pois, em algumas escolas, as decisões de caráter administrativo e pedagógico ainda estão pautadas nas velhas relações autoritárias, na maioria das vezes, centralizadas na figura do diretor e de um grupo muito pequeno da comunidade escolar, na sua maioria, professores, ficando ainda muito restrito à participação dos pais e alunos e funcionários. Esses aspectos são confirmados nos depoimentos da equipe gestora das escolas participantes da pesquisa.

Essa constatação não deve ser motivo para se abrir mão dos conselhos escolares como instância importante para o aperfeiçoamento da gestão democrática da escola pública. Gracindo (2004) nos diz que a forma mais adequada para que o conselho escolar possa exercer a sua função de acompanhamento do processo educativo é sendo corresponsável pelo planejamento da escola, pela implantação e avaliação do seu projeto político-pedagógico.

\section{A gestão em escolas estaduais do ensino médio: os desafios do cotidi- ano escolar ${ }^{1}$}

Nesta parte do artigo, serão analisados os dados relativos à gestão desenvolvida em escolas estaduais do ensino médio, do estado do Rio Grande do Norte, considerando duas dimensões: o projeto político-pedagógico e os conselhos escolares.

\section{Os desafios para consolidação do projeto político-pedagógico}

Um primeiro tema considerado na pesquisa foram os motivos que desencadearam a elaboração do ppp na escola, indicados por ordem de importância pelas equipes gestoras: cumprir a legislação, definir as ações da escola, dinamizar o 
trabalho coletivo e o envolvimento da comunidade. O gráfico a seguir especifica como a situação foi constatada no conjunto das escolas pesquisadas.

\section{Gráfico 1}

Motivação da equipe gestora para a elaboração do PPP

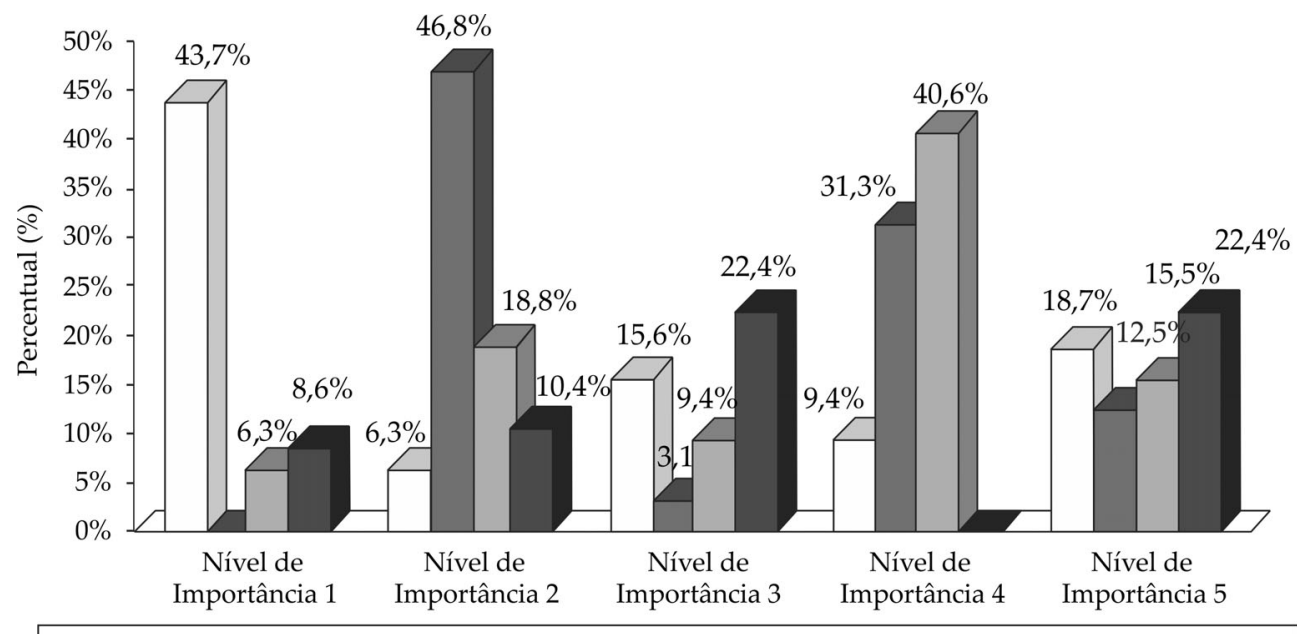

$\square$ Cumprir a Legislação $\square$ Definir as Ações da Escola $\square$ Dinamizar o Trabalho Coletivo

$\square$ Envolver a Comunid./Escola

Fonte: Pesquisa - Fatores que Interferem na Produtividade do Ensino Médio: um Estudo no RN/2010.

Obs.: 0 número 1 da escala representa o maior nível de importância, variando na ordem descrescente até o número 5 .

Como se pode observar, pelos dados sistematizados no gráfico apresentado, um número significativo de componentes da equipe gestora $(43,7 \%)$ atribuiu nível de importância 1 à determinação legal como motivação para a elaboração do PPP, $8,6 \%$ indicaram o envolvimento da comunidade escolar como prioridade 1 e 6,3\% evidenciaram a dinamização do trabalho coletivo. No que se refere ao nível de prioridade 2, a definição das ações da escola é apontada por 46,8\% dos gestores como o principal motivo que mobilizou a escola para elaboração do PPP, enquanto 18,8\% consideram que foi a dinamização do trabalho coletivo; $10,4 \%$ o envolvimento da comunidade escolar; e 6,3\%, o cumprimento da legislação. No nível 3, a equipe gestora apontou $22,4 \%$ como prioritário o envolvimento da comunidade; $15,6 \%$, o cumprimento de uma legislação específica; $9,4 \%$, a dinamização do trabalho pedagógico; e 3,1\%, a definição das ações da escola. No nível 4, os dados evidenciam, com um percentual de $40,6 \%$, que o principal motivo para a elaboração do PPP, indicado pela equipe gestora, foi a dinamização do trabalho coletivo; 31,3\% informam que foi a definição das ações da escola e 9,4\% entendem que foi o cumprimento da legislação. Nesse nível de prioridade, o envolvimento da comunidade escolar não apareceu nas respostas dos entrevistados. No último nível de prioridade, nível 5, as motivações 
são mais equânimes e estão assim distribuídas: $22,4 \%$ dos componentes da equipe gestora indicaram o envolvimento da comunidade como motivação da elaboração do PPP; $18,7 \%$ indicaram o cumprimento da legislação; $15,5 \%$, a dinamização do trabalho pedagógico; e 12,5\%, a definição das ações da escola.

A análise dos dados do gráfico 1 permite fazer algumas inferências, tomando como base as respostas da equipe gestora das escolas pesquisadas. Na opinião desses atores, a determinação legal foi o primeiro fator motivador da elaboração do pPp nas escolas; além de aparecer como a prioridade no nível 1, esse fator encontra-se de forma significativa em todos os outros níveis. Esse dado se configura como um aspecto importante, visto que a legislação cria, pelo menos do ponto de vista formal, as condições iniciais que desafiam os educadores a elaborar o PPP, instrumento essencial para a gestão da escola, conforme já evidenciado nas discussões desenvolvidas em parte precedente deste artigo. Não se pode descartar que a formulação de um arcabouço legal, na década de 1990, prevendo a necessidade da elaboração do PPP, tenha representado um avanço para esse campo do conhecimento e um desafio para os profissionais que atuam no âmbito micro do sistema educacional, uma vez que, culturalmente, estavam acostumados a uma forma de gestão burocrática centralizada na figura do diretor.

Por outro lado, também, pode apresentar uma limitação no sentido de imputar um modelo de gestão homogêneo para as unidades escolares. A imposição legal transcende os espaços escolares, não sendo, quase sempre, fruto de um desejo da comunidade escolar; pelo contrário, é decorrente de políticas elaboradas em âmbito central sem a devida participação dos atores escolares, os quais se restringem à sua execução, descaracterizando assim o espaço escolar como lugar de concepção da prática educativa. Há, nessa situação, uma tendência da equipe gestora participante da pesquisa de considerar a determinação legal como um ato de autoritarismo, o que pode resultar no posicionamento de não considerar o legado normativo como algo importante para definir as normas do jogo democrático. Essa posição é recorrente nas informações prestadas pelos componentes da equipe gestora, visto que considera essa determinação legal como uma imposição do nível central à escola, limitando a sua autonomia na definição de sua proposta pedagógica.

A prevalência da indicação legal, pela equipe gestora, em relação às outras opções referentes aos aspectos pedagógicos para a elaboração do ppr na escola, pode ser uma das evidências da forma autoritária como esse mecanismo da gestão democrática foi concebido nas escolas de ensino médio do RN. O fato de sua elaboração não ter partido de um desejo da comunidade escolar, conforme as informações registradas, dificulta o envolvimento dos profissionais em efetivar as ações do PpP e comprova os argumentos formulados por autores como Veiga (2003) e Dourado (2004), para quem a gestão democrática não se reduz somente a uma questão técnica, mas se configura como um ato político. 
Nesse sentido, cabe registrar, segundo informações da equipe gestora, que as escolas priorizam o planejamento estratégico, induzido por ações governamentais por meio do Plano de Desenvolvimento da Escola, inclusive com financiamento específico para esse fim. O programa consiste em estabelecer metas e indicadores de desempenho para medir a eficácia e a eficiência das escolas. Esse programa é organizado segundo os princípios do gerencialismo e vem sendo desenvolvido de forma a imprimir à escola uma lógica administrativa centrada no controle de resultados pela implantação de um sistema de monitoramento e avaliação das ações, que são definidas a partir de indicadores estabelecidos externamente. Essa lógica difere daquela que deve orientar o PPP, que, conforme os argumentos apresentados ao longo deste artigo, funda-se no trabalho coletivo da escola em todas as suas fases.

Como forma de organizar as ações da escola, o ppp aparece indicado, pela equipe gestora, como prioridade no nível 2 , como uma motivação significativa para a sua elaboração, reaparecendo no nível 3, 4 e 5 com um percentual mais baixo, o que pode ser uma evidência de que uma parte importante dos componentes da equipe gestora já despertou para a necessidade de elaborar um ppr que permita definir, com clareza, as ações que a escola precisa desenvolver, para enfrentar a complexa tarefa de educar e de lidar com as diversidades socioeconômicas e educacionais da clientela que a ela tem acesso.

Há o reconhecimento, por parte dos membros da equipe gestora das escolas pesquisadas, quanto ao compromisso com a elaboração do ppp nas unidades escolares. Em suas respostas, é recorrente o posicionamento de que a elaboração desse mecanismo importante da gestão democrática é tarefa de todos os que fazem parte da escola. No entanto, argumentam que esse compromisso fica comprometido, uma vez que existem muitas demandas para as escolas decorrentes de gama de programas que são chamadas a desenvolver. Essas demandas, acrescidas da falta de tempo, da capacitação inadequada dos gestores e das novas exigências do trabalho escolar, como afirmam os componentes da equipe gestora, têm imposto limitações para avanços mais significativos na gestão democrática das escolas. Na maioria das instituições pesquisadas, existe o PPP, embora, como afirmam os componentes da equipe gestores, não seja considerado pelos profissionais da escola na elaboração de seus planos específicos de trabalho, o que pode ser considerada uma evidência de que ele não está se constituindo no instrumento delineador das ações escolares.

O trabalho coletivo só é indicado pela equipe gestora de forma mais significativa no nível 4 de prioridade na elaboração do Ppr. Para os sujeitos da pesquisa, as escolas não priorizam o trabalho coletivo; pelo contrário, há, nas unidades escolares, a prevalência de práticas individualistas muito arraigadas no seu cotidiano, bem como a dificuldade de conciliar os horários de trabalho desses profissionais para envolvê-los nessa tarefa. Falta, ainda, segundo a equipe gestora, motivação 
dos profissionais para promover mudanças na escola, diante das condições adversas de trabalho nela existentes. Isso pode se constituir em fatores limitativos para o desenvolvimento de ações coletivas. Nesse sentido, perde-se a oportunidade de se estabelecer, na escola, uma cultura de participação, para instaurar uma forma de organização do trabalho pedagógico e administrativo que busque minimizar os conflitos e eliminar as relações competitivas, corporativas e autoritárias, rompendo com a rotina do mando pessoal e racionalizado da burocracia e permitindo as relações horizontais no interior da escola.

Essa dificuldade de desenvolver ações coletivas foi, também, expressa no que concerne à participação da comunidade nas atividades da escola, tendo sido considerada pela equipe gestora como de menor importância, visto que apresentou uma indicação muito baixa em todos os níveis da escala, aparecendo, somente, nos níveis de importância 3 e 5.

Ainda em relação ao PPP, o gráfico a seguir registra as informações sobre os níveis de participação dos sujeitos escolares na sua coordenação, elaboração e sistematização.

\section{Gráfico 2}

Atores que participaram da coordenação, elaboração e sistematização do PPP

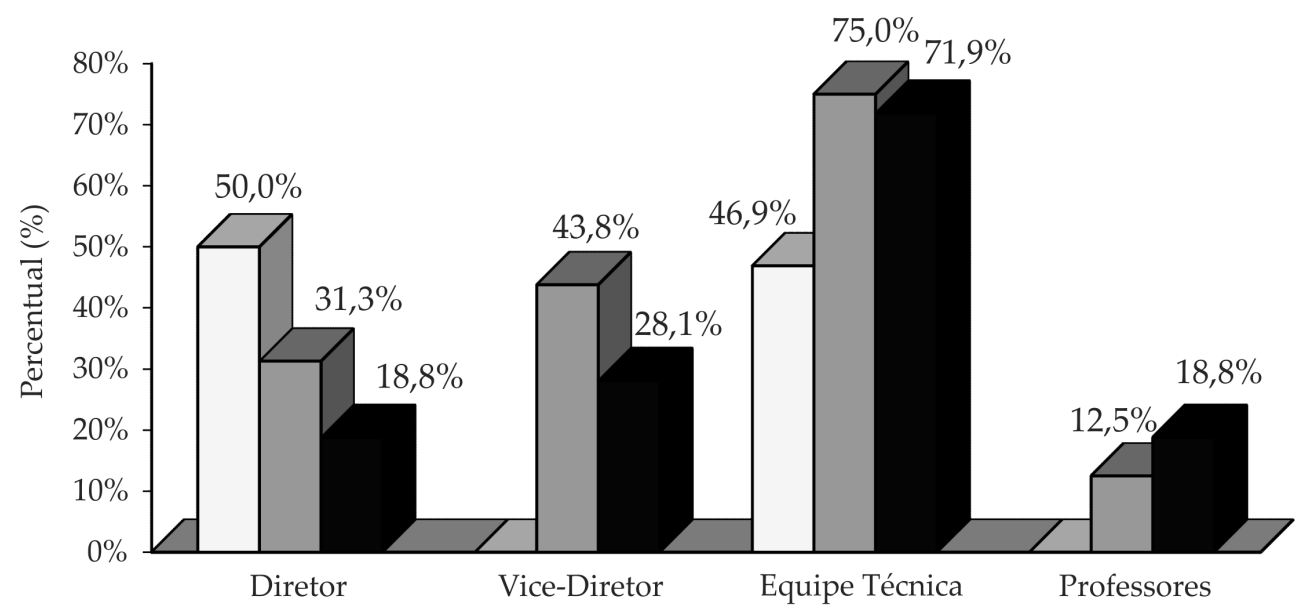

Coordenação da Elaboração do PPP प Elaboração do PPP — Sistematização do PPP

Fonte: Pesquisa: Fatores que Interferem na Produtividade do Ensino Médio: um estudo no RN/2010.

As informações fornecidas pela equipe gestora evidenciam que a participação dos atores na construção do ppp variou de acordo com as etapas e as funções que eles exercem na escola. No que concerne aos diretores, constata-se que $50 \%$ participaram 
da coordenação do processo; 31,3\%, da elaboração e das discussões do ppp e apenas $18,8 \%$, da sistematização do documento final. Em relação aos vice-diretores, evidenciou-se, segundo informações da equipe gestora, que $43,8 \%$ participaram da etapa de elaboração, nenhum deles coordenou o processo de construção do PPP e, apenas, 28,1\% participaram da sistematização do documento. Nesse processo, o principal protagonista, em todas as etapas do PPP, foi a equipe técnico-pedagógica com a participação de $75 \%$ no processo de elaboração, 46,9\% na coordenação e $71,9 \%$ na sistematização do PPP. Os professores - um dos segmentos importantes nesse processo - tiveram, segundo informação da equipe gestora, pouca participação, considerando que somente $12,5 \%$ participaram da elaboração, $18,8 \%$ da sistematização e em nenhuma escola os professores chegaram a coordenar a elaboração do PPP. Os grandes ausentes do processo, conforme dados fornecidos pela equipe gestora, são os funcionários $(9,4 \%)$, alunos $(3,1 \%)$ e a comunidade $(3,1 \%)$; esses atores tiveram uma atuação insignificante em todo o processo, participando, exclusivamente, da sistematização do documento.

Os dados fornecidos pela equipe gestora mostram uma realidade recortada por dificuldades no que concerne à participação do coletivo na elaboração do PPP. Conforme fica evidente nos dados sistematizados, a elaboração desse mecanismo importante da gestão democrática tem envolvimento preponderante da equipe técnica das escolas, com uma menor participação do diretor e do vice-diretor. Esse nível de participação dos dirigentes escolares na elaboração do ppp reafirma uma situação histórica em relação à atuação do gestor escolar no que diz respeito à dimensão pedagógica da gestão. A equipe gestora informa, ainda, que se envolve muito com o cotidiano administrativo da escola, não dedicando parte do seu tempo para assumir a coordenação da unidade escolar em todas as suas dimensões.

Esse quadro desenhado evidencia uma situação em que determinados setores da escola (principalmente a equipe técnica) assumem a hegemonia no processo de elaboração do PPP, não tendo estes a capacidade de sensibilizar o coletivo para o engajamento de todos os profissionais nessa complexa tarefa de conceber um projeto que atenda às atuais demandas colocadas para a instituição escolar. Um projeto concebido dessa forma tem pouca chance de se transformar em um guia útil para orientar a ação da escola. Desse modo, os planos de trabalho das diversas equipes não se orientam para a consecução das decisões contidas no ppr sobre os vários ângulos requeridos pelo projeto de educação nele delineado.

O PpP deve propiciar organicidade à escola e, nesse sentido, deve constituir um meio de engajamento coletivo para integrar ações dispersas, criar sinergias no sentido de buscar soluções alternativas para diferentes momentos do trabalho pedagógico-administrativo, desenvolver o sentimento de pertença, mobilizar os protagonistas para a explicitação de objetivos comuns, definindo o rumo das ações 
a serem desencadeadas, fortalecer a construção de uma coerência comum, mas indispensável, para que a ação coletiva produza seus efeitos esperados (Dourado, 2004; Veiga, 2003).

A construção de um processo de gestão democrática implica repensar a lógica de organização e participação nas escolas. É fundamental, pois, discutir os mecanismos de participação na escola, suas finalidades e a definição de ações e metas a serem construídas coletivamente pelos diferentes segmentos que a compõem ou dela devem participar.

\section{O conselho escolar no contexto da gestão}

No que se refere à implantação e às funções dos conselhos escolares nas escolas de ensino médio, registra-se a existência desse órgão em todas as unidades pesquisadas. O gráfico seguinte permite observar os motivos que levaram as escolas a criar esses conselhos.

\section{Gráfico 3}

Opinião da equipe gestora sobre os motivos para criação do conselho escolar

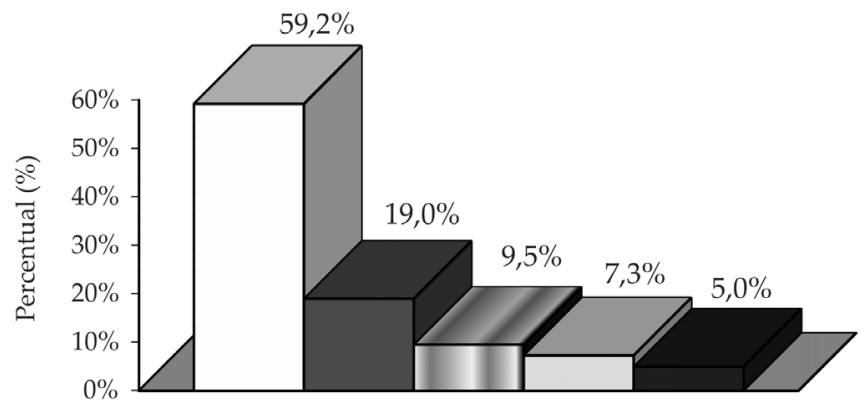

$\square$ Decreto do Governo do Estado

$\square$ Sem Conhecimento

Iniciativa da Direção da Escola $\square$ Iniciativa dos Profissionais da escola - Outras Formas

Fonte: Pesquisa: Fatores que Interferem na Produtividade do Ensino Médio: um estudo no RN/2010.

Quanto às razões que levaram as escolas a implantar o conselho, conforme indicação da equipe gestora, prevaleceu a exigência legal como principal motivo para a instituição desse órgão nas unidades. É muito elevado o percentual de sujeitos $(59,2 \%)$ que afirmam que a implantação dos conselhos, em escolas do ensino médio pesquisadas, foi determinada por uma exigência de um Decreto da Secretaria de Educação; apenas 19\% dos entrevistados informaram que o conselho escolar foi implantado por iniciativa da direção da escola; 9,5\% atribuem essa iniciativa aos 
profissionais da escola. Esse resultado confirma a tendência já apresentada quando da elaboração do PPP, ou seja, há uma concepção de gestão democrática que se impôs de forma verticalizada aos sistemas escolares, dificultando a efetivação da gestão democrática no interior dessas instituições, descaracterizando o princípio constitutivo desse modelo que é a participação política da comunidade escolar na tomada de decisões internas. Os órgãos colegiados, criados para possibilitar a divisão do poder na escola e limitar a autoridade do gestor escolar, ficaram fragilizados, uma vez que a exigência legal é o principal elemento instigador da implantação desses órgãos nas unidades pesquisadas.

Dessa forma, fica comprometida a possibilidade de uma ação administrativa com vistas à construção coletiva, que exige a participação de toda a comunidade escolar nas decisões do processo educativo, o que resultará na democratização das relações desenvolvidas na escola, contribuindo para o aperfeiçoamento administrativo e pedagógico.

É importante que o coletivo escolar compreenda que o conselho cria estratégias de alargamento da participação, da autonomia e da representatividade, como uma das possibilidades de consolidação da democracia no interior das escolas, e que essa concepção de gestão estabelece uma organização escolar horizontalizada, baseada no princípio da participação direta dos segmentos da comunidade escolar no processo de decisão, de planejamento de decisões compartilhadas.

A natureza dos conselhos escolares também foi outra dimensão considerada na análise. Nesse aspecto, é possível perceber que não há consenso entre os entrevistados sobre a natureza que eles assumem nas escolas, conforme se pode observar no gráfico a seguir:

\section{Gráfico 4}

Opinião da equipe gestora sobre a natureza do conselho escolar

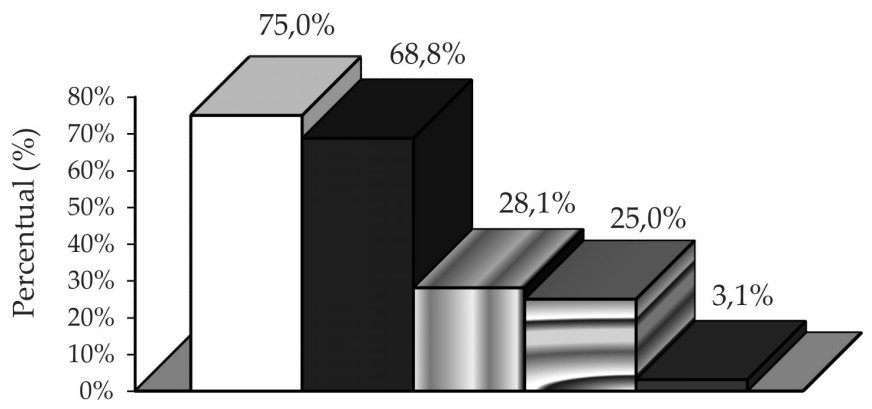

Consultivo Deliberativo $\square$ Normativo $\square$ Executivo $\square$ Propositivo

Fonte: Pesquisa: Fatores que Interferem na Produtividade do Ensino Médio: um estudo no RN/2010. 
As informações fornecidas pela equipe gestora indicam que os conselhos nas escolas assumem preponderantemente funções consultivas $(75 \%)$ e deliberativas $(68,8 \%)$; em menor proporção, a natureza normativa $(28,1)$ e executiva $(25 \%)$ e, em menor proporção, ainda, a natureza propositiva $(3,1 \%)$. A prioridade atribuída pela equipe gestora à função consultiva do conselho sinaliza para o caráter cartorial e formalista de como os conselhos foram instituídos, o que dificulta o seu funcionamento de maneira adequada. A natureza consultiva, atribuída por esses profissionais ao conselho, determina sua posição secundária no processo de gestão da escola. Segundo Riscal (2010), os problemas com relação aos conselhos emergem da sua concepção centralizadora, enfatizando a presença, às vezes, de um único líder: o diretor da escola. Quando se mantém, de forma implícita, a hierarquização das relações de poder na escola, entre dirigentes e dirigidos, cria-se a ilusão de decisões coletivas, sem que elas, realmente, aconteçam.

No entanto, há um percentual expressivo de informantes que caracterizam a atuação do conselho em sua função deliberativa, o que pode representar um avanço significativo na sua organização. Essa é uma função importante dos conselhos, pois, entre as suas atribuições, está a finalidade de garantir o controle e a fiscalização pelos seus beneficiários das ações efetivadas na escola. Todavia, vários fatores têm contribuído para dificultar essas ações nas unidades escolares, entre elas: as práticas tradicionais e clientelistas de gestão, reduzida capacidade organizacional, dependência financeira da escola e incapacidade político-institucional de transformar as práticas administrativas de acordo com uma nova perspectiva de gestão democrática (Werle, 2003; Riscal, 2010).

Outras funções foram atribuídas aos conselhos pelos entrevistados: a normativa, a executiva e a propositiva. Nestas, mais que nas outras, os conselhos ainda têm muito que avançar para atingir seus objetivos, considerando que a relação assimétrica estabelecida entre os membros que os compõem pode funcionar como elemento inibidor dessas funções, porque, para que elas se materializem, necessitam, por parte dos conselheiros, de conhecimentos técnicos para que possam propor ou normatizar ações no âmbito da escola.

Os colegiados poderão vir a se constituir em uma estratégia de democratização da gestão escolar, na medida em que forem exploradas todas as possibilidades de oportunizar a seus membros uma efetiva participação direta na concepção, execução e avaliação dos projetos da escola, permitindo a ampliação da consciência dos indivíduos e dos grupos que deles fazem parte.

Embora tenha-se evidenciado, nas escolas pesquisadas, a busca de construir um caminho da gestão democrática, observou-se que, no seu cotidiano, estão em construção mecanismos da gestão gerencial expressos, entre outros, no estabelecimento 
de parcerias com outros órgãos do setor público (37,5\%), com instituições privadas $(31,3 \%)$ e do terceiro setor $(6,3 \%)$. Além disso, verificam-se, no funcionamento e organização das escolas, os indícios de uma lógica organizacional centrada no controle dos resultados e uma preocupação com os resultados obtidos nas avaliações externas, que passam a orientar, inclusive, ações pedagógicas, como a oferta de "cursos preparatórios" para que os alunos obtenham sucesso nesses exames, visto que eles são, também, determinantes do seu financiamento.

\section{Considerações finais}

A gestão democrática das escolas públicas encontra-se na agenda da política educacional do governo brasileiro, notadamente, a partir das últimas décadas do século xx e se amplia nos anos iniciais do século xxı. Esse mesmo mecanismo temse apresentado como uma demanda dos setores organizados dos educadores que, historicamente, pressionaram o poder público para criar mecanismos de gestão democrática para a administração das unidades escolares. Tal mecanismo (em função de uma série de lutas históricas) encontra-se, hoje, assegurado nos principais instrumentos legais e de planejamento que conformam a política educacional concebida pelo governo brasileiro.

Entretanto, as escolas de ensino médio que compuseram a pesquisa, no que concerne a sua gestão, contraditoriamente, vivenciam, nesses últimos anos, uma situação de perplexidade, visto que convivem, no mesmo espaço, com orientações situadas em polos contraditórios. O conflito se estabelece na medida em que esses profissionais, como afirmam os entrevistados, são desafiados a trabalhar com dois mecanismos distintos de gestão: o projeto político-pedagógico - concebido no âmbito da escola, embora com limitações, e que estaria, pelas suas características, teoricamente, mais alinhado a uma vertente de gestão democrática - e o Plano de Desenvolvimento da Escola (PDE Escola) - concebido com base em regras e orientações elaboradas por agentes externos à escola e que devem ser seguidas, sem muito espaço, para uma atuação dos sujeitos escolares.

No cotidiano das escolas de ensino médio pesquisadas, constata-se, a partir de informações fornecidas pela equipe gestora, que, cada vez mais, o segundo mecanismo (PDE) tem sobressaído e influenciado o modo de gestão das unidades de ensino. Isso decorre de uma série de fatores entre os quais se podem citar a destinação de recursos específicos para a realização das atividades, o controle exercido pelos órgãos externos para garantir o cumprimento das metas e os mecanismos internos de organização e acompanhamento das ações. Tal fato concorreu para que a equipe gestora se dedicasse mais às atividades de caráter administrativo, restando pouco tempo para cuidar dos aspectos pedagógicos, inerentes ao seu trabalho. Esse é o 
quadro geral observado nas escolas do ensino médio, no estado do Rio Grande do Norte, que compuseram o campo empírico da pesquisa.

Mesmo tendo observado essa situação, cabe realçar que todos os profissionais entrevistados consideram o mecanismo da gestão democrática como o mais adequado para gerir o espaço público em nível micro. Teoricamente, portanto, não há argumentação contrária à necessidade e à importância da gestão democrática para imprimir um gerenciamento mais adequado às unidades escolares. A cultura da gestão democrática encontra-se, desse modo (pelo menos, em nível do discurso), presente no cotidiano das escolas públicas e a sua defesa, como forma de melhorar a qualidade do ensino público, é fortemente argumentada pelos gestores escolares, o que pode, também, representar certa contradição entre o discurso e as práticas desenvolvidas no âmbito das instituições.

A pesquisa constatou que passos importantes foram dados pelas escolas públicas para propiciar as bases institucionais, visando a edificar um processo de gestão democrática. Esses mecanismos institucionais propiciaram às escolas ganhos importantes no sentido de conceber e vivenciar novos mecanismos de gestão democrática em um espaço, até então, dominado por práticas autoritárias e avessas à participação dos agentes escolares e da comunidade.

Embora tenham sido constatados esses avanços iniciais em relação à gestão democrática no espaço das unidades escolares, o estudo constata uma série de fragilidades que precisam ser consideradas e superadas para o aperfeiçoamento desse mecanismo no âmbito das escolas públicas. Com base nos dados estatísticos sistematizados e nas anotações contidas no diário de campo, destacam-se as seguintes limitações no processo de construção da gestão das escolas do ensino médio do Rio Grande do Norte que participaram da pesquisa: pouca cultura da escola na vivência do trabalho coletivo, resultando em precário envolvimento dos atores escolares na vida da instituição, e a dificuldade de dinamizar os espaços institucionais organizados para criar as condições favoráveis ao aprimoramento da gestão democrática.

Os conselhos escolares - espaços essenciais para imprimir um caráter qualitativo à gestão democrática - não conseguiram assumir essa função, devido a uma série de problemas; a falta de sensibilização e compreensão sobre a importância do projeto político-pedagógico para a dinâmica interna da escola resulta no envolvimento limitado dos atores escolares em todas as suas fases (elaboração, execução e avaliação); condições de trabalho limitadoras da ação mais efetiva dos agentes educacionais na organização e no funcionamento da gestão da escola; pouco investimento dos órgãos governamentais e da própria escola em processos formativos para qualificar melhor os agentes educacionais em relação às possibilidades e aos conhecimentos sobre a gestão democrática; pouca cultura de avaliação institucional, o que 
dificulta um acompanhamento mais adequado das ações da escola e de seus resultados. No geral, as práticas administrativas, nas escolas pesquisadas, se apresentam eivadas por certo ativismo, indicando que há muito a ser feito para se instaurar no espaço escolar uma gestão de melhor qualidade.

\section{Nota}

1. Os dados utilizados nesta parte do artigo foram organizados com base em pesquisa realizada em sete escolas de três municípios do estado do Rio Grande do Norte (Natal, Mossoró e Caicó). No desenvolvimento da pesquisa foram consideradas três dimensões de análise: gestão escolar, formação inicial e continuada dos professores e prática pedagógica. Para fins deste artigo, foi considerada apenas a dimensão da gestão escolar, contemplando dois tipos de levantamentos. No primeiro momento, foi realizada uma revisão bibliográfica sobre o tema e analisados documentos oficiais que normatizam a gestão nas escolas públicas. No segundo momento, foram coletados dados sobre a situação da gestão escolar nas unidades de ensino médio junto a 76 professores, sendo 46 de escolas de Natal, 14 de escolas de Mossoró e 14 de escolas de Caicó; e 32 componentes da equipe gestora, assim, distribuídos: Natal (17), Mossoró (8) e Caicó (7). Neste artigo, foram considerados, apenas, os dados relativos à gestão escolar coletados junto aos componentes da equipe gestora (diretor, vice-diretor, equipe pedagógica). Os dados foram coletados no ano de 2009, por meio de um questionário contendo questões abertas e fechadas, formuladas em função de dois eixos de análise da pesquisa (projeto político-pedagógico e conselho escolar) e aplicados diretamente nas escolas pelos pesquisadores. Foi também utilizado um diário de campo em que foram registradas as ocorrências observadas nas escolas durante a aplicação do instrumento. Os dados gerais da pesquisa foram processados com a utilização do software Modalisa versão 4.5 - programa de computação que auxilia no tratamento dos dados, melhorando a sua qualidade e, sobretudo, facilitando a interpretação das informações. Foram produzidas tabelas simples para todas as perguntas aplicadas à equipe gestora. Cada tabela foi apresentada com os valores absolutos e percentuais, além de barras gráficas do tipo Diagrama de Pareto, a fim de facilitar a análise de cada questão aplicada.

\section{Referências}

ABRUCIO, F.L. Os avanços e os dilemas dos modelos pós-burocráticos: a reforma da administração pública à luz da experiência internacional recente. In: BresSERPereira, L.C.; Spink, P. A reforma do Estado e a administração pública gerencial. 5. ed. Rio de Janeiro: Fundação Getúlio Vargas, 2003. p. 173-199.

ANDERSON, P. Balanço do neoliberalismo. In: SAder, E.; Gentili, P. Pós-neoliberalimo: as políticas sociais e o estado democrático. Rio de Janeiro: Paz \& Terra, 1995. p. 9-23.

BARROSO, J. Autonomia e gestão das escolas. Lisboa: Editorial do Ministério da Educação, 1998.

BARZELAY, M. Atravessando la burocracia: una nueva perspectiva de la administración pública. México, DF: Fondo de Cultura econômica, 1998.

BORDIGNON, G. Gestão democrática da educação. In: Gestão democrática da educação. Ministério Brasília, DF: MEC, out. 2005. p. 3-13. (Boletim 19). 
BRASIL. Constituição (1988). Constituição da República Federativa do Brasil. Brasília, DF: Senado Federal, 1988.

BRASIL. Congresso Nacional. Lei n. 9.394, de 20 de dezembro de 1996, que estabelece as diretrizes e bases da educação nacional. Brasília, DF, 1996.

BRESSER-PEREIRA, L.C. Reforma do Estado para a cidadania: a reforma gerencial brasileira na perspectiva internacional. São Paulo: Editora 34; Brasília, DF: ENAP, 1998.

CABRAL NETO, A.; ALMEIDA, M.D. Educação e gestão descentralizada: conselho diretor, caixa escola, projeto político-pedagógico. Em Aberto, Brasília, DF, v. 17, n. 72, p. 35-45, jun. 2000.

CENTRO Latino-Americano de Administración para el Desarrollo (CLAD). Responsabilização na nova gestão pública latino-americana (introdução). In: BresserPereira, L.C; Grau, N.C. Responsabilização na administração pública. São Paulo: Clad/ FUNDAP, 2006. p. 13-69.

CURY, C.R.J. Gestão democrática da educação pública. In: Gestão democrática da educação. Brasília, DF: MEC, out. 2005. p. 14-19. (Boletim 19).

DOURADO, L.F. Gestão democrática da escola: movimentos, tensões e desafios. In: Silva, A.M.M.; Aguiar, M.A.S. (Org.). Retrato da escola no Brasil. Brasília, Df: CNTE, 2004. p. 59-74.

FERREIRA, N.S.C. Repensando e ressignificando a gestão democrática da educação na cultura globalizada. Educação \& Sociedade, Campinas, v. 15, n. 89, p. 1227-1249, set./dez. 2004.

GETE, B.O.L. La evolución de la gestión pública: la nueva gestión pública. Madrid: Pearson Educación, 2001.

GRACINDO, R.V. Projeto político-pedagógico: retrato da escola em movimento. In: Silva, A.M.M.; Aguiar, M.A. (Org.). Retrato da escola no Brasil. Brasília, DF: CNTE, 2004. p. 163-175.

HARVEY, D. A condição pós-moderna. São Paulo: Loyola, 1992.

KUENZER, A.Z. Ensino de 2ํo grau: o trabalho como princípio educativo. São Paulo: Cortez, 1992.

LUSTOSA DA COSTA, F. Reforma do Estado e contexto brasileiro: uma crítica do paradigma gerencialista. Rio de Janeiro: Fundação Getúlio Vargas, 2010.

LÜCK, H. Perspectivas da gestão escolar e implicações quanto à formação de seus gestores. Em Aberto, Brasília, DF, v. 17, n. 72, p. 11-34, jun. 2000. 
LÜCK, H. Concepções e processos democráticos de gestão educacional. Petrópolis: Vozes, 2006.

MACHADO, L.R.S. Mudanças tecnológicas e a educação da classe trabalhadora. In: Machado, L.R.S. Educação e trabalho. Campinas: Papirus, 1994.

OFFE, C. A ingovernabilidade: sobre o renascimento das teorias conservadoras da crise. In: OfFe, C. Problemas estruturais do Estado capitalista. Rio de Janeiro: Tempo Brasileiro, 1984. p. 236-260.

PARAMIO, L. Reforma política y reforma del Estado. Revista del CLAD, Reforma y Democracia, Venezuela, n. 30, p. 63-82, oct. 2004.

QUIRÓS, M.M. Responsabilização pelo controle de resultados. In: Bresser-PereIRA, L.C; Grau, N.C. Responsabilização na administração pública. São Paulo: Clad/FundaP, 2006. p. 165-216.

RISCAL, S.A. Considerações sobre o conselho escolar e seu papel mediador e conciliador. In: Luız, M.C. (Org.). Conselho escolar: algumas concepções e propostas de ação. São Paulo: Xamã, 2010. p. 23-46.

SANTOS, B.S. Para uma reinvenção solidária e participativa do Estado. In: BRESSERPereira, L.C; Wilheim, J.; Sola, L. (Org.). Sociedade e Estado em transformação. São Paulo; Brasília: UNESP; IMESP; ENAP, 1999. p. 243-247.

VASCONCELOS, C.S. Planejamento: projeto de ensino-aprendizagem e projeto político-pedagógico. 9. ed. São Paulo: Libertad, 2003.

VEIGA, I.P.A. (Org.). Projeto político pedagógico da escola: uma construção possível. São Paulo: Papirus, 1995.

VEIGA, I.P.A. Escola: espaço do projeto político pedagógico. Campinas: Papirus, 2003.

WERLE, F.O.C. Conselhos escolares: implicações na gestão da escola básica. Rio de Janeiro: DP\&A, 2003.

Recebido em 22 de julho de 2011.

Aprovado em 30 de agosto de 2011. 